\title{
In vivo systemic toxicity assessment of an oxidized dextrin-based hydrogel and its effectiveness as a carrier and stabilizer of granular synthetic bone substitutes
}

\author{
Isabel Pereira $\mathbb{C}^{1},{ }^{1}$ Sónia Fraga, ${ }^{2,3}$ Luís Maltez, ${ }^{4,5}$ João Requicha, ${ }^{5}$ Luísa Guardão, ${ }^{6}$ Joana Oliveira, ${ }^{6}$ \\ Justina Prada, ${ }^{4,5}$ Helena Alves, ${ }^{7}$ José Domingos Santos, ${ }^{8}$ João Paulo Teixeira, ${ }^{2,3}$ \\ José Eduardo Pereira, ${ }^{4,5}$ Raquel Soares, ${ }^{9}$ Francisco Miguel Gama ${ }^{1}$ \\ ${ }^{1} \mathrm{CEB}$ - Centre of Biological Engineering, University of Minho, Campus de Gualtar, 4710-057, Braga, Portugal \\ ${ }^{2}$ Departamento de Saúde Ambiental, Instituto Nacional de Saúde Dr. Ricardo Jorge, 4000-053, Porto, Portugal \\ ${ }^{3}$ EPIUnit - Instituto de Saúde Pública, Universidade do Porto, 4050-600, Porto, Portugal \\ ${ }^{4}$ CECAV - Animal and Veterinary Research Centre, University of Trás-os-Montes e Alto Douro, 5001-801, Vila Real, Portugal \\ ${ }^{5}$ Department of Veterinary Sciences, University of Trás-os-Montes e Alto Douro, 5001-801, Vila Real, Portugal \\ ${ }^{6}$ Animal House Unit, Faculty of Medicine, University of Porto, 4200-319, Porto, Portugal \\ ${ }^{7}$ Departamento de Promoção da Saúde e Prevenção de Doenças Não Transmissíveis, Instituto Nacional de Saúde Dr. Ricardo \\ Jorge, 4000-053, Porto, Portugal \\ ${ }^{8}$ REQUIMTE-LAQV, Departamento de Engenharia Metalúrgica e Materiais, Faculdade de Engenharia, Universidade do Porto, \\ Rua Dr. Roberto Frias, Porto, 4200-465, Portugal \\ ${ }^{9}$ Department of Biomedicine, Unit of Biochemistry, Faculty of Medicine, i3S - Instituto de Investigação e Inovação em Saúde, \\ University of Porto, Porto, 4200-319, Portugal
}

Received 16 December 2018; revised 25 February 2019; accepted 22 March 2019

Published online 12 April 2019 in Wiley Online Library (wileyonlinelibrary.com). DOI: 10.1002/jbm.a.36683

\begin{abstract}
The worldwide incidence of bone disorders is raising, mainly due to aging population. The lack of effective treatments is pushing the development of synthetic bone substitutes (SBSs). Most ceramic-based SBSs commercially available display limited handling properties. Attempting to solve these issues and achieve wider acceptance by the clinicians, granular ceramics have been associated with hydrogels (HGs) to produce injectable/moldable SBSs. Dextrin, a lowmolecular-weight carbohydrate, was used to develop a fully resorbable and injectable $\mathrm{HG}$. It was first oxidized with sodium periodate and then cross-linked with adipic acid dihydrazide. The in vivo biocompatibility and safety of the dextrin-based HG was assessed by subacute systemic toxicity and skin sensitization tests, using rodent models. The results showed that
\end{abstract}

the HG did not induce any systemic toxic effect, skin reaction, or genotoxicity, neither impaired the bone repair/regeneration process. Then, the HG was successfully combined with granular bone substitute, registered as Bonelike $(250-500 \mu \mathrm{m})$ to obtain a moldable/injectable SBS, which was implanted in tibial fractures in goats for 3 and 6 weeks. The obtained results showed that HG allowed the stabilization of the granules into the defect, ensuring effective handling, and molding properties of the formulation, as well as an efficient cohesion of the granules. () 2019 Wiley Periodicals, Inc. J Biomed Mater Res Part A: 107A: 1678-1689, 2019.

Key Words: dextrin, injectable hydrogel, synthetic bone substitutes, bone regeneration, in vivo biocompatibility

How to cite this article: Pereira I, Fraga S, Maltez L, Requicha J, Guardão L, Oliveira J, Prada J, Alves H, Santos JD, Teixeira JP, Pereira JE, Soares R, Gama FM. 2019. In vivo systemic toxicity assessment of an oxidized dextrin-based hydrogel and its effectiveness as a carrier and stabilizer of granular synthetic bone substitutes. J Biomed Mater Res Part A 2019:107A:1678-1689.

\section{INTRODUCTION}

Bone is a dynamic and highly vascularized tissue with a unique capacity to heal and regenerate itself throughout the lifetime of an individual. However, in some situations where the template for an orchestrated regeneration fails, clinical procedures are needed. ${ }^{1}$ Currently, the standard procedure to treat bone defects is the autograft, which consists in harvesting a small amount of bone tissue from the patient and its transplantation to the defect site. Despite this procedure has the best clinical outcome, explant site pain and morbidity, and limited availability represent main limitations. Allografts (bone tissue from other individuals or corpses) or

Additional Supporting Information may be found in the online version of this article.

Correspondence to: F. M. Gama; e-mail: fmgama@deb.uminho.pt

Contract grant sponsor: Fundação para a Ciência e a Tecnologia; contract grant number: SFRH/BD/ 90066/2012 and UID/BIM/04293/2013 and UID/BIO/04469/2013

Contract grant sponsor: Fundo Europeu de Desenvolvimento Regional (FEDER); contract grant number: NORTE-01-0145-FEDER-000004 and NORTE01-0145-FEDER-000012 and NORTE-01-0247-FEDER-003262 and Norte-07-0202-FEDER-038853 
xenografts (bone tissue from other species) can overcome these issues, but the risk of immune reactions, transmission of diseases, and low availability of tissue banks limit their utilization. ${ }^{1,2}$ In this respect and considering that the worldwide incidence of bone disorders and conditions has trended steeply upward, mainly due to aging population, alloplastic biomaterials, such as synthetic bone substitutes (SBSs) have appeared as a valid alternative to tissue transplants. ${ }^{1,3}$

Ceramic-based SBSs are widely used as bone substitutes in the clinical practice. ${ }^{4}$ Many of these commercially available products are presented in granular form. ${ }^{1}$ They are difficult to handle and to fit into the defects, namely in irregular defects and the granules can be washed out from the implanted site by body fluids and, consequently, migration of granular particles to the surrounding tissues occurs, which can cause adverse or unexpected events., ${ }^{3,5}$ Moreover, the micromovements of the granules within the defect can affect the formation of new bone tissue.

In order to potentiate the clinical application of the granular SBSs, they have been combined with hydrogels (HGs). ${ }^{7-9}$ HGs can ensure granules cohesiveness/stabilization into the bone defect. They can also serve as space holders to prevent granule packing and allow easier bone ingrowth, ${ }^{10,11}$ and provide moldable properties, allowing the clinicians to handle and shape the formulations into the bone defects without leakage of the granules. Moreover, the combination of bioactive properties of granular ceramics with the elastomeric properties of HGs, results in composites with better mechanical properties, such as higher extensibilities. ${ }^{12-18}$ One of the major advantages in using HGs is the possibility to develop injectable formulations of bone substitutes. From a clinical point of view, injectability of biomaterials for the regeneration of bone defects offers several clinical and economic advantages as compared to solid, prefabricated implants. Using these flowable materials, complete filling of the defect site can be established by means of minimally invasive techniques..$^{3,8,9,19}$ In particular, stimuli-responsive HGs have been appointed as the best candidates to achieve this goal. Their ability to gel in situ in response to external physical or chemical stimuli-as temperature, $\mathrm{pH}$ or UV light-allow HGs mixed with ceramics to be administered as flowable viscous liquids (sol state) into the bone defect, then turning into standing HGs (gel state). ${ }^{9}$

Our research group has been developing and characterizing a fully resorbable and injectable dextrin-based HG which was intended to perform as a multifunctional platform, enabling the combination with stem cells and other bioactive agents, during clinical procedures. ${ }^{20-23}$ To obtain the HG, dextrin was first oxidized with sodium periodate to produce dialdehydes, which then reticulate with adipic acid dihydrazide $(\mathrm{ADH}){ }^{20}$ We proposed that in situ forming dextrin-based HG would be a suitable carrier for ceramic granules in clinical applications.

The development of biomaterials for medical applications includes extensive preclinical testing in order to demonstrate their safety and efficacy according to the regulatory agencies requirements. ${ }^{24}$ Thus, in the present study, the systemic toxicity of the HG was assessed, as well as the bone histocompatibility and skin sensitization, using rodent models. Then, the HG was associated with granular ceramics (250-500 $\mu \mathrm{m})$ for the development of a moldable and injectable bone substitute, and the effectiveness of the HG to stabilize the granules into the defect was evaluated in a goat tibial fracture.

\section{MATERIAL AND METHODS}

\section{Chemicals}

Dextrin used in this work was TACKIDEX B167 (Batch E 1445), generously provided by Roquette (Lestrem, France). All chemicals used were of highest purity or analytical grade available. Sodium $m$-periodate, diethylene glycol, ADH, Triton $\mathrm{X}-100$, low melting point (LMP) agarose, Tris base, Freund's complete adjuvant (FCA), and sodium dodecyl sulfate (SDS), sodium carbonate $\left(\mathrm{Na}_{2} \mathrm{CO}_{3}\right)$, calcium hydrogen phosphate $\left(\mathrm{CaHPO}_{4}\right)$, calcium fluoride $\left(\mathrm{CaF}_{2}\right)$, diphosphorus pentaoxide $\left(\mathrm{P}_{2} \mathrm{O}_{5}\right)$ and poly(vinyl alcohol) (PVA), formaldehyde were purchased from Sigma-Aldrich (St. Louis, MO). Absolute ethanol, sodium hydroxide $(\mathrm{NaOH})$, sodium chloride $(\mathrm{NaCl})$, hydrochloric acid ( $\mathrm{HCl})$, Tris base, Giemsa's azur eosin methylene blue, ethylenediaminetetraacetic acid disodium salt ( $\mathrm{Na}_{2}$ EDTA), and hydrogen peroxide solution $\left(\mathrm{H}_{2} \mathrm{O}_{2}\right)$ were obtained from Merck (Darmstadt, Germany). Invitrogen SYBR Gold was purchased from Thermo Fisher Scientific (Waltham, MA). Sterile phosphate buffered saline (PBS) solution without calcium and magnesium was purchased to Biochrom $\mathrm{GmbH}$ (Berlin, Germany), normal melting point (NMP) agarose was supplied by Bioline (London, UK), and LymphoPrep was obtained from STEMCELL Technologies (Vancouver, Canada).

\section{Material preparation}

Dextrin oxidation. Dextrin oxidation was performed as previously described by Pereira et al. ${ }^{25}$ Briefly, aqueous solutions of dextrin $(2 \% \mathrm{w} / \mathrm{v})$ were oxidized with sodium $m$-periodate, to yield the theoretical degree of oxidation of $40 \%$, at room temperature, with stirring, in the dark. After $20 \mathrm{~h}$, the oxidation reaction was stopped by adding drop wise an equimolar amount of diethylene glycol, to reduce any unreacted periodate. Sodium $m$-periodate and diethylene glycol were removed by ultrafiltration, using a membrane with a molecular weight cutoff 1000 Da (Merck Millipore, Billerica, $\mathrm{MA}$ ), and then lyophilized.

Preparation of dextrin-based HG. Oxidized dextrin (ODEX) was dissolved in PBS buffer (30\% w/v) and the solution was sterilized by gamma irradiation, using a ${ }^{60} \mathrm{Co}$ source, at $20 \mathrm{kGy}$ (2 kGy/h), at room temperature, by IONISOS (Dagneux, France). ADH was dissolved also in PBS buffer $(3.76 \% \mathrm{w} / \mathrm{v})$ and sterilized by filtration, using filters with pore $0.22 \mu \mathrm{m}$ (Pall Corporation, MI). For the cross-linking reaction, ODEX and ADH solutions were mixed with volume ratio 7:3.

Preparation of BONElike granules. Ceramic powder was synthesized according to the method described elsewhere. ${ }^{26,27}$ Briefly, $\mathrm{P}_{2} \mathrm{O}_{5}-\mathrm{CaO}$-based glass with the chemical composition of $65 \mathrm{P}_{2} \mathrm{O}_{5}-15 \mathrm{CaO}-10 \mathrm{CaF}_{2}-10 \mathrm{Na}_{2} \mathrm{O}$ (mol \%) was prepared by mixing the appropriate quantities of $\mathrm{Na}_{2} \mathrm{CO}_{3}, \mathrm{CaHPO}_{4}, \mathrm{CaF}_{2}$, and $\mathrm{P}_{2} \mathrm{O}_{5}$ in a platinum crucible, and 
then heating it at $1450^{\circ} \mathrm{C}$ for $90 \mathrm{~min}$ in a glass furnace. The prepared glass was crushed in an agate mortar and sieved to a granule size below $50 \mu \mathrm{m}$. Bonelike was obtained by adding 2.5 wt $\%$ of bioglass to the previous prepared hydroxyapatite (HAP). The Bonelike powder was mixed with the microcrystalline cellulose and PVA and the resulting suspension was poured into alumina $\left(\mathrm{Al}_{2} \mathrm{O}_{3}\right)$ plates, dried in a woven at $60^{\circ} \mathrm{C}$ for 2 days and then the samples were sintered at $1300^{\circ} \mathrm{C}$ using a heating rate of $4^{\circ} \mathrm{C} / \mathrm{min}$, followed by natural cooling inside the furnace. Finally, using standard milling and sieving techniques, Bonelike granules with particle size between 250 and $500 \mu \mathrm{m}$ were obtained. Throughout this work, Bonelike will be abbreviated to BL.

Association of Bonelike granules to dextrin-based HG. In order to set the higher concentration of BL granules which can be loaded into the HG without compromising the extrusion process and granules' stability and moldability, different concentrations of BL were tested $\left(30,40\right.$, and $60 \%\left(\mathrm{w}_{\mathrm{BL}} / \mathrm{v}_{\mathrm{HG}}\right)$ of granules). For each formulation, all components (BL, ODEX, and $\mathrm{ADH}$ ) were mixed, transferred into $2 \mathrm{~mL}$ syringes and incubated for $30 \mathrm{~min}$. To evaluate the injectability of the formulations, the syringe was fixed vertically on the texture analyzer TA-XT2i (Stable Micro Systems, UK). During the test, while using a load cell of $5 \mathrm{kgf}$, the syringe piston was pushed at a velocity of $1 \mathrm{~mm} / \mathrm{s}$, through a distance of $10 \mathrm{~mm}$ and the extrusion force was measured. The test was performed in triplicate.

\section{Animals}

All the animal testing procedures were in conformity with the European norms for animal welfare (European Directive 2010/63/EU) and with the approval of the Portuguese Veterinary Authorities (Direção-Geral de Alimentação $e$ Veterinária), in accordance with the Portuguese legislation (Portaria 1005/92) and European Communities Council Directive of November 1986 (86/609/EEC). Humane endpoints were followed in accordance to the OECD Guidance Document on the Recognition, Assessment and Use of Clinical Signs as Humane Endpoints for Experimental Animals Used in Safety Evaluation. ${ }^{28}$ Adequate measures were taken to minimize pain and discomfort, considering humane endpoints for animal suffering and distress.

\section{Subacute systemic toxicity test}

The potential of the HG to cause adverse systemic reactions was evaluated in Wistar rats (Charles River Laboratories Inc.) for 3 weeks, and was performed according to requirements and guidances described by ISO 10993-11. ${ }^{29}$ Twenty rats of both genders, 8-9 weeks old, were randomly divided in test group (HG) and control group (PBS). One femoral defect was induced per animal [Fig. 1(A)], and HG (test group) or PBS (control group) were then injected. For the creation of the femoral defect, the pelvic limb from the lumbar midline to the knee was shaved and aseptically prepared with gluconate chlorhexidine. A longitudinal skin incision beginning over greater trochanter extending down the lateral side was made, exposing the tensor fascia lata, which was then dissected. A deep dissection was performed splitting vastus lateralis. Retractors were placed at the proximal femur and then bone surface was exposed with subperiosteal dissection. A lateral unicortical $3 \mathrm{~mm}$ circular defect was drilled under irrigation using a round diamond turbine bur (iM3, Republic of Ireland), and then the materials (PBS or HG) were placed and fitted in the defects. After, the surgical wound was closed in two layers using a 4-0 glyconate reabsorbable suture (Monosyn; B. Braun, Portugal) for muscle and for the skin. Animals received analgesic medication for 5 days and antibiotic treatment for 6 days. After 3 weeks of implantation surgery, the animals were anesthetized and then euthanized with an intraperitoneal injection of sodium pentobarbital (Eutasil; CEVA, Portugal).

During the experimental period of 3 weeks, mortality, body weight, and clinical signs (respiratory, motor activities, convulsion, reflexes, ocular and cardiovascular signs, salivation, piloerection, analgesia, muscle tone, gastrointestinal, and skin signs) were observed and recorded. Immediately before sacrificing the animals, the blood samples were collected for hematological and biochemical parameters determination and genotoxicity assessment. After sacrifice, all animals were subjected to a necropsy examination and the adrenals, brain, epididymides, heart, kidneys, liver, ovaries, spleen, testes, thymus, and uterus were collected and weighed. Spleen, liver, kidneys, lungs, pancreas, and femur were fixed in $10 \%$ neutral-buffered formalin for further histopathological examination.
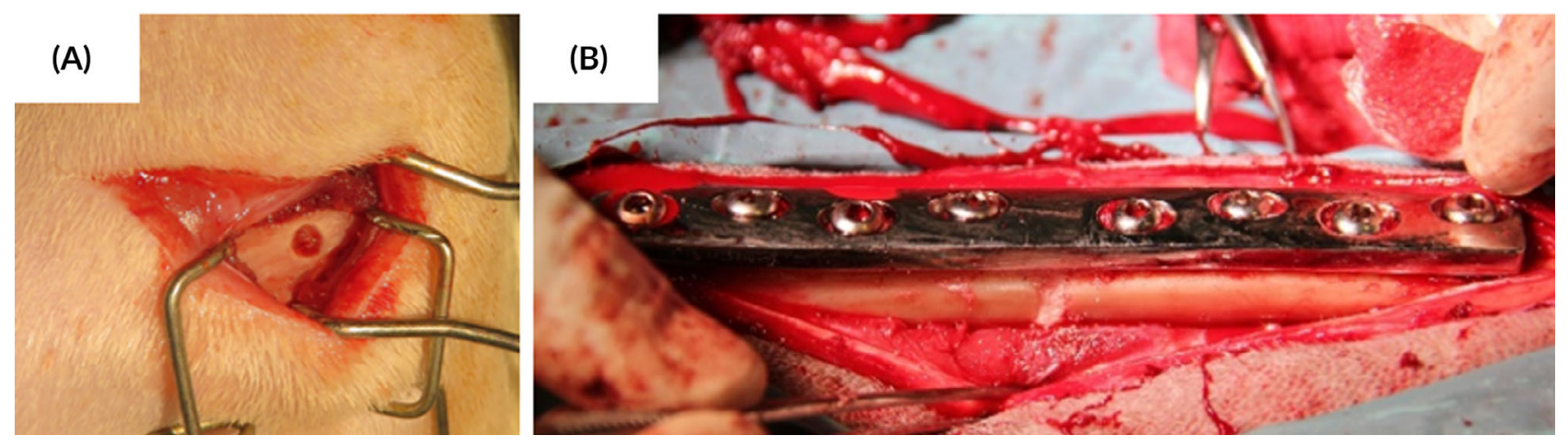

FIGURE 1. Bone defects performed in the animals: (A) femoral defect induced in Wistar rats for subacute systemic toxicity test and (B) segmental bone defect in the diaphysis of the tibia created in goats, filled with the HG + BL formulation. 
Genotoxicity assay. Comet assay, also known as the singlecell gel electrophoresis assay was performed in rat wholeblood and isolated peripheral blood mononuclear cells (PBMC) to evaluate the DNA damage. For whole blood, $5 \mu \mathrm{L}$ of each sample (two replicates per sample) was suspended in $995 \mu \mathrm{L}$ of PBS, and centrifuged at $400 \times g$ for $3 \mathrm{~min}$. The obtained pellets were mixed in $100 \mu \mathrm{L}$ of $1 \%(\mathrm{w} / \mathrm{v}$ ) LMP agarose and layered, in duplicate, onto dry microscope slides (VWR, Darmstadt, Germany) precoated with 1\% (w/v) NMP agarose, in duplicate (four replicates per sample). For PBMC, $100 \mu \mathrm{L}$ of venous blood sample (two replicates per sample) was suspended in $100 \mu \mathrm{L}$ of PBS, and gently layered over $150 \mu \mathrm{L}$ of LymphoPrep. Then, samples were centrifuged at $400 \times g$ for $5 \mathrm{~min}$, the PBMC layer was retrieved, resuspended in PBS up to $1 \mathrm{~mL}$, and centrifuged at $400 \times g$ for $3 \mathrm{~min}$. The obtained pellets were mixed in $100 \mu \mathrm{L} 1 \%$ (w/v) LMP agarose and also layered onto dry microscope slides precoated with $1 \%(\mathrm{w} / \mathrm{v}$ ) NMP agarose (four replicates per sample). After gel solidification, rat whole blood and PBMC slides were immersed in $200 \mu \mathrm{M} \mathrm{H}_{2} \mathrm{O}_{2}(20 \mathrm{~min})$ and $25 \mu \mathrm{M} \mathrm{H}_{2} \mathrm{O}_{2}$ (3 min), respectively, protected from light and kept in the refrigerator, served as positive controls. All the slides were then placed in a Coplin jar and immersed in icecold lysis solution $\left(2.5 \mathrm{M} \mathrm{NaCl}, 100 \mathrm{mM} \mathrm{Na}{ }_{2}\right.$ EDTA, $10 \mathrm{mM}$ Tris base, $10 \mathrm{M} \mathrm{NaOH}, \mathrm{pH} 10$, supplemented with $1 \%$ Triton$\mathrm{X} 100$ ) for $1.5 \mathrm{~h}$ at $4^{\circ} \mathrm{C}$, protected from light to lyse the cells and separate DNA from histones. For unwinding of the DNA, all slides were immersed in freshly prepared electrophoresis buffer (200 mM Na${ }_{2}$ EDTA, $0.3 \mathrm{M} \mathrm{NaOH} \mathrm{pH} \mathrm{>} \mathrm{13)} \mathrm{in} \mathrm{the} \mathrm{elec-}$ trophoresis unit for $40 \mathrm{~min}$ at $4{ }^{\circ} \mathrm{C}$, followed by electrophoresis for $20 \mathrm{~min}$ at $30 \mathrm{~V}$ and $300 \mathrm{~mA}$. Then, the gels were washed with $\mathrm{H}_{2} \mathrm{O}$, fixed with ethanol 70 and $96 \%$ for $15 \mathrm{~min}$, each at room temperature. After air-drying the slides overnight, DNA was stained with a $0.07 \%$ SYBR Gold solution. The slides were coded, and one scorer performed the comet analysis using a fluorescence microscope (Nikon Eclipse E400 microscope attached to an epifluorescence illuminator Nikon C-SHG1) with $400 \times$ magnification and the image analysis software Comet Assay IV (Perceptive Instruments, Suffolk, UK). The \% DNA in the comet tail (tail intensity) and the olive tail moment (OTM) were used as a measure of the amount of DNA damage. At least 200 cells, per animal, were scored (50 cells for each replicate gel).

Histological processing. Spleen, liver, kidneys, lungs, pancreas, and femur from Wistar rats were routinely processed, dehydrated and embedded in paraffin wax, in a Shandon automatic tissue processor Hypercenter XP. Consecutive $3 \mu \mathrm{m}$ sections were cut and stained with hematoxylin and eosin (HE) and kept for histopathological analysis. Prior to tissue processing, femurs were decalcified with Surgipath decalcifier II Leica, for $48 \mathrm{~h}$. Images were acquired using a Nikon VR microscope connected to a Nikon VR digital camera DXM1200.

\section{Skin sensitization test}

The maximization sensitization test was performed to determine the potential of the HG to produce skin sensitization in guinea pigs, according to ISO $10993-10^{30}$ and OECD $406^{31}$ guidelines. Fifteen Dunkin Hartley guinea pigs (seven males and eight females) (Charles River Laboratories Inc.) were used for the experiment, with 10 animals in the test group and five in the control group. The test consisted of three phases: intradermal induction phase, topical induction phase, and challenge phase. The pelage of guinea median back region (for the intradermal or topical application) and flank region (for the challenge dose) was shaved. Then (intradermal induction phase), three pairs of intradermal injections of $100 \mu \mathrm{L}$ were given in the median back region: (1) PBS mixed with FCA (1:1 v/v), (2) HG; and (3) HG mixed with FCA $(1: 1 \mathrm{v} / \mathrm{v})$; in the control group, HG was substituted by PBS (vehicle). After 6 days, all animals received a topic application of $10 \%$ SDS, in the injection area, in order to create a local irritation. On the next day, a gauze fully loaded with 2.5-fold diluted HG (for test group) and PBS (for control group) was applied in the same area, and held in contact by an occlusive dressing for $48 \mathrm{~h}$. The challenge phase was conducted 14 days after the topical application, in which the diluted HG was applied in right flank region of all animals, using a loaded gauze $\left(1 \times 1 \mathrm{~cm}^{2}\right)$ and covered with an occlusive dressing. The dressings were removed after $24 \mathrm{~h}$. The appearance of the challenge skin areas of the animals was observed 24 and $48 \mathrm{~h}$ after removal of the dressings. The description and grade of the skin reactions for erythema and oedema was done according to the Magnusson and Kligman grading scale. $^{30}$

\section{Application of the Bonelike granules combined to dextrin-based HG in bone defects}

The assessment of the effectiveness of the dextrin-based HG to mold and stabilize Bonelike granules in bone defects was performed in a tibia fracture on a goat model. For this purpose, adult goats $(n=24)$ were used and randomly divided into two groups: control (empty defect) and test (HG + BL). Briefly, the periosteum was elevated on the medial tibial shaft and the eight-hole stainless-steel dynamic compression plate was fixed in the distal segment in order to perform the holes to insert the $4.5 \mathrm{~mm}$ screws in the distal segment. Then, the plate was removed, and the transverse osteotomy of the tibia was performed using a high-speed oscillating saw. After that, a width $4 \mathrm{~mm}$ metallic spacer was inserted between the two segments of the tibia to create a uniform defect. Then, the plate was screwed first to the distal segment and then the holes were drilled, and the fixation was done in the proximal segment. The spacer was removed, and the defect was filled with $\mathrm{HG}+\mathrm{BL}$ [Fig. 1(B)]. The soft tissues were closed in two layers with resorbable sutures. After surgery, X-ray images were obtained. The goats were set free in a $25 \mathrm{~m}^{2}$ open space and allowed to move without restriction after surgery and received analgesic medication for 4 days and antibiotic treatment for 7 days. The goats were randomly sacrificed 3 and 6 weeks $(n=6)$ after surgery with a lethal intravenous injection of $40 \%$ sodium pentobarbital (Euthasol, ESTEVE, Spain). The tibia was then harvested and fixed in $4 \%$ formaldehyde solution for further analysis. 
Microcomputed tomography analysis. Microcomputed tomography (micro-CT) scans were taken for qualitative evaluation of the new bone formed in tibial defects, using the micro-CT 100 scanner (Scanco Medical AG, Brüttisellen, Switzerland), which operated with a cone beam originating from a $5 \mu \mathrm{m}$ focal-spot X-ray tube. The photons were detected by a charged-coupled device-based area detector and the projection data were computer reconstructed into a $2058 \times 2058$ image matrix. A $0.5 \mathrm{~mm}$ aluminum filter was used for taking optimized images. For each sample, at least 1500 projections $/ 180^{\circ}$ of X-rays (90 kVp, $155 \mu \mathrm{A}$, integration time $300 \mathrm{~ms}$, scanning time $56 \mathrm{~min}$ ) were acquired.

\section{Statistical analysis}

Experimental data were presented as mean \pm standard deviation (SD). Statistical analysis and graphs were performed using the Prism version 6.1 (GraphPad Software Inc., La Jolla, CA). Statistical analysis of data was performed by two-tailed $t$ test. Significance was accepted at a $p$ value $<0.05$.

\section{RESULTS}

\section{Subacute systemic toxicity assessment}

The systemic toxicity of the HG after implantation in a bone defect was evaluated over a period of 3 weeks. During this experiment, no animal mortalities were observed for any of the test or control groups, all presenting normal vital parameters and behavior. The body weight of animals of both genders in the test groups did not vary significantly from the respective control group (Table S1). The gain in body weight in all the test groups was comparable to that of the control group. Thus, no HG-related effects were observed in relation to mortality, clinical signs, and body weight changes.

Hematology and biochemical analyses were also performed in all animals to investigate toxic effects in tissues, organs, and other systems. The biochemical profile (Table S2) revealed no significant changes in the various biochemical parameters assessed. These results corroborated well with the hematological profiles of animals in the test group of both genders compared with the control group (Table S3). Despite a significant reduction in the eosinophils levels $(p<0.01)$ observed in females of the test group, the values are within the normal range. ${ }^{32}$

Systemic effects were also evaluated in the animals during necropsy, where careful macroscopic assessment of the internal organs was carried out in order to confirm the clinical observations performed during the study period. The internal organs of the animals from test groups presented normal topography and morphological features, without any signs of necrosis, congestion, and abnormal accumulations. The determination of organ coefficient $\left(\% \mathrm{w}_{\text {organ }} / \mathrm{w}_{\text {body }}\right)$ confirmed that HG did not promote any toxicity in vital organs, since no statistical difference to the control group was observed (Fig. S1). Additionally, careful histopathological analysis was performed for kidneys, liver, lungs, pancreas, and spleen, which did not exhibit any alteration in the normal cellular architecture of the organs of both male and female animals (Fig. 2 and Fig. S2).

\section{Genotoxicity assessment}

The comet assay is a versatile, sensitive, and rapid method for measuring DNA strand breaks at the level of individual cells. $^{33}$ Both whole-blood cells and PBMC were evaluated and the results are presented in Table I. Tail intensity (\%) and OTM values of whole-blood cells and PBMC from the animals treated with $\mathrm{HG}$ were not significantly different in relation to the respective control group, in animals of both genders, suggesting that $\mathrm{HG}$ did not induce DNA damage. On the other hand, cells exposed to a $\mathrm{H}_{2} \mathrm{O}_{2}$ solution (positive control) displayed a significant increase in tail intensity (\%) and OTM $(p<0.001)$.

\section{Assessment of HG implant site}

The local effects were evaluated through macroscopic observation of the femurs and histological analysis to the implanted site. Macroscopic observation was conclusive for the absence of abnormalities, necrosis, infection, or changes in the normal structure of the femurs. Histological analysis was performed in order to assess the bone tissue response to injectable HG. Representative histological images of tissues stained with HE are presented in Figure 3. No HG was found in the defect site. The histological appearance of the HG-treated defects from both genders was identical to the defects in the control group. The defects were occupied by connective tissue with variable neovascularization, containing active osteoblasts at the margins of the defect. The presence of inflammatory cells was not observed in any sample, nor necrosis or fatty infiltrate. The performed defect was noncritical, which means that it will heal spontaneously over the time.

\section{Skin sensitization assessment}

The guinea pig has been the animal of choice for the detection of sensitizing activity of chemicals and medical devices for several decades. Among the guinea pig assays recommended by ISO 10993-10, the Guinea Pig Maximization Test is the most sensitive one. ${ }^{30,31}$ In this test, the guinea pigs (both in test and control groups) did not show signs of erythema and oedema, or any adverse skin response in the challenge skin areas at 24 and $48 \mathrm{~h}$ after removal of the dressings (Fig. S3). The numerical grading for erythema and oedema was zero.

\section{Association of Bonelike granules to dextrin-based HG}

HG was associated with different loads of BL, as to determine the higher amount that may be used without compromising the extrusion process, the granules' stability, and the handling/molding of the final formulation. Figure 4 (A) displays the appearance of the formulations after complete gelation of the $\mathrm{HG}$ when combined with different concentrations of BL $(30,40$, and $60 \% \mathrm{w} / \mathrm{v})$. The HG was able to envelop and aggregate the granules well. The formulation containing $60 \%$ of BL presents a perfect cohesion, the granules being homogeneously distributed over the HG, contrary to what was verified with lower concentrations (30 and $40 \%$, whose granules started to settle at the bottom of the syringe, during the gelation time process, resulting in a more heterogeneous formulation). For superior concentrations, the 
Male Control

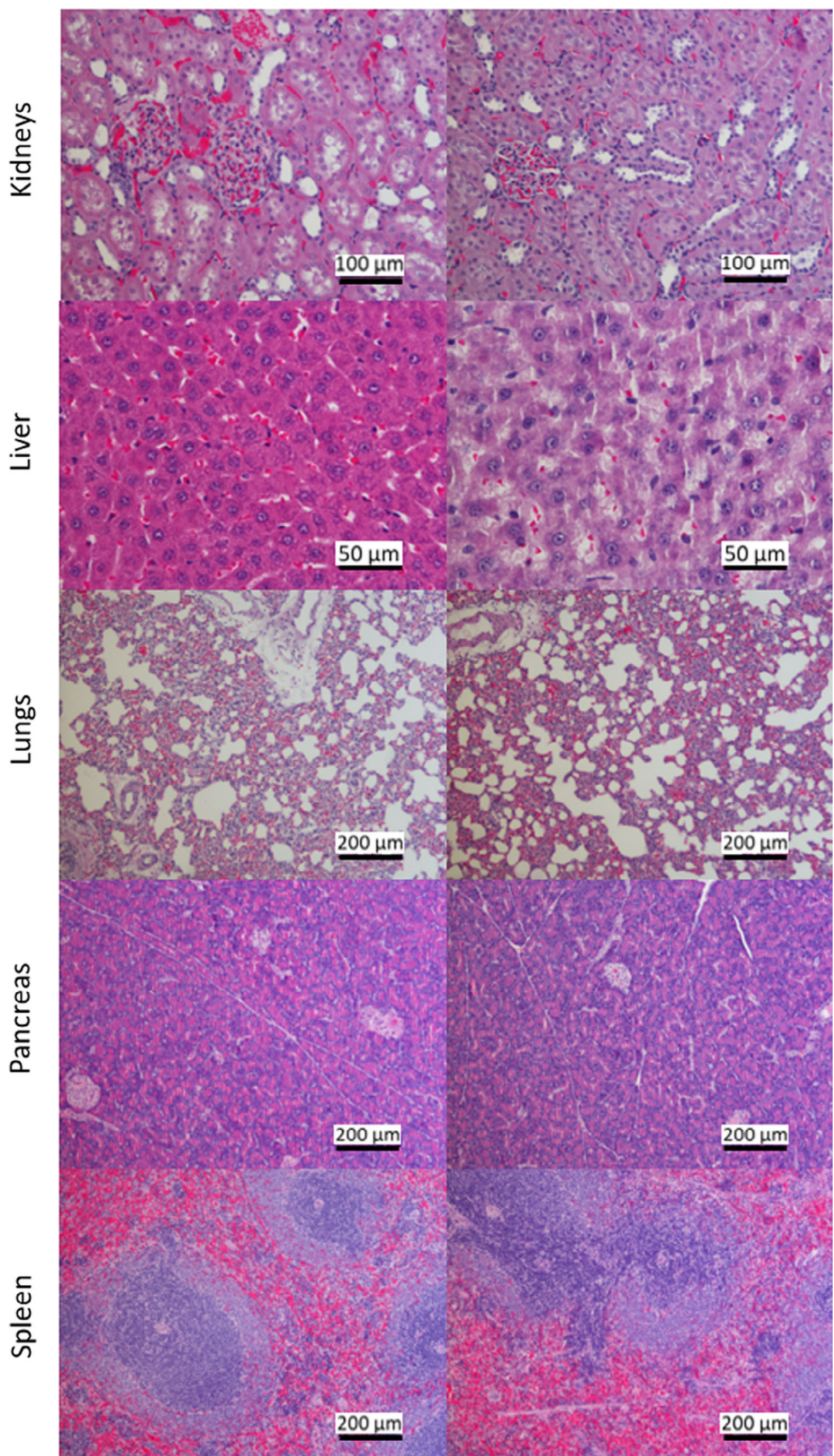

FIGURE 2. Representative photographs of histopathological examination, after HE staining, of kidneys, liver, lungs, pancreas, and spleen of control and test male groups, 3 weeks after surgery. 
TABLE I. Comet Assay Analysis of DNA Damage in Whole-Blood Cells and PBMC of Female and Male Rats Exposed to the Hydrogel (Test Group) and PBS (Control Group), at 3 weeks After Surgery

\begin{tabular}{|c|c|c|c|c|}
\hline & \multicolumn{2}{|c|}{ Whole Blood } & \multicolumn{2}{|c|}{ PBMC } \\
\hline & Tail intensity (\%) & Olive tail moment & Tail intensity (\%) & Olive tail moment \\
\hline Female control & $10.72 \pm 3.66$ & $1.14 \pm 0.43$ & $8.29 \pm 1.87$ & $0.86 \pm 0.22$ \\
\hline Female test & $9.32 \pm 0.99$ & $0.99 \pm 0.15$ & $6.21 \pm 0.60$ & $0.55 \pm 0.11$ \\
\hline Male control & $10.18 \pm 2.25$ & $1.11 \pm 0.33$ & $7.72 \pm 1.88$ & $0.73 \pm 0.18$ \\
\hline Male test & $10.55 \pm 0.33$ & $1.07 \pm 0.03$ & $8.36 \pm 2.90$ & $0.83 \pm 0.37$ \\
\hline Positive control & $27.72 \pm 3.12^{*}$ & $4.70 \pm 1.37^{*}$ & $40.00 \pm 7.81 *$ & $7.53 \pm 2.66^{*}$ \\
\hline
\end{tabular}

Hydrogen peroxide $\left(\mathrm{H}_{2} \mathrm{O}_{2}, 200 \mu \mathrm{M}\right.$ and $25 \mu \mathrm{M}$ for whole-blood cells and PBMC, respectively) was used as positive control. Results are presented as mean $\pm \mathrm{SD}$ ( $n=5$ replicates per group). Data were analyzed by two-tailed $t$ test: $* p<0.001$ versus control group.

HG was unable to aggregate/stabilize all the granules. Moreover, with $60 \%$ of $\mathrm{BL}$, the resulted formulation displayed suitable malleability and handling properties after the gelation process, allowing the surgeon to manipulates/shape it, without dispersing the granules or breaking the HG.

In an injectable system, it is essential to study the extrusion force required to inject the material. The injectability curves of the formulations with different concentrations of BL are shown in Figure 4(B). The three formulations presented similar extrusion profiles. Initially, a drastic rise in the force required was observed, which corresponds to the beginning of the extrusion, followed by the plateau which corresponds to the continuous and uniform flow of the material. The formulation containing 30,40 , and $60 \%$ of BL displayed maximum extrusion forces of $5.89,5.83$, and $7.13 \mathrm{~N}$, respectively. There was a slight increase in the extrusion force when using $60 \%$ of $\mathrm{BL}$, since a greater force is required to extrude a larger quantity of granules.

\section{Assessment of the effectiveness of the dextrin-based HG to mold and stabilize Bonelike granules in bone defects}

The surgical procedure was simple, fast, and well tolerated by the animals. Immediately after recover from surgery, the animals were able to walk and support weight in the treated limb. The surgeon prepared himself the formulation and controlled the gelling process and was able to implant easily and quickly the formulation. As the defect displayed only two vertical walls [Fig. 1(B)], the formulation was implanted during the final phase of the gelation process, when it displayed as a "moldable paste," by using a surgical spatula. The formulation was well shaped to the defects and allowed the complete filling of the bone gap, without leakage of the granules. It is important to note that the main goal of this defect model was to evaluate the capability of the HG to stabilize BL granules into the bone defect, as well as the moldable properties of the final formulation.

During the postsurgery period, no complications were observed, such as infections, abscesses and allergic reactions, and the surgical skin incision healed normally. X-ray images were obtained after surgery [Fig. 5(A)], while micro-CT images were acquired after animal sacrifice at 3 and 6 weeks [Fig. 5(B)]. The radiographic images of the control group presented a radio-transparent gap in the defect site after surgery, which remained after 3 and 6 weeks, as can be seen in micro-CT reconstruction images [Fig. 5(B)], indicating that the bone healing process was not complete. Regarding the test group, the radiographic images taken postsurgery presented a radio-opacity in the defect site, corresponding to $\mathrm{BL}$ granules. After 3 and 6 weeks [Fig. 5(B)], BL granules are still in place and did not fall down to the medullar cavity. The
Female Control

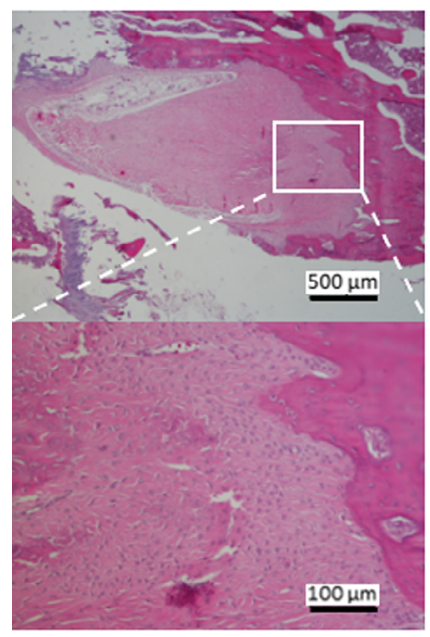

Female Test

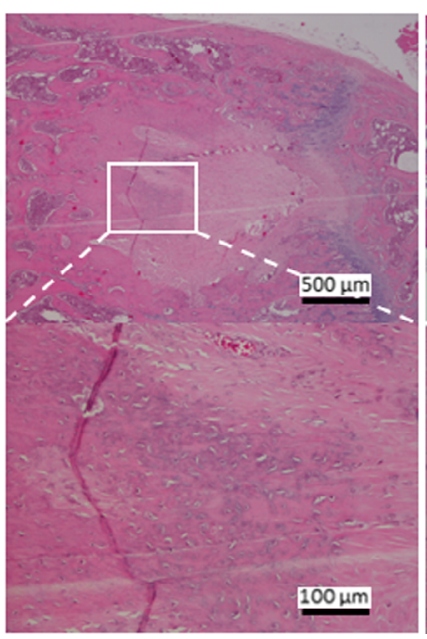

Male Control

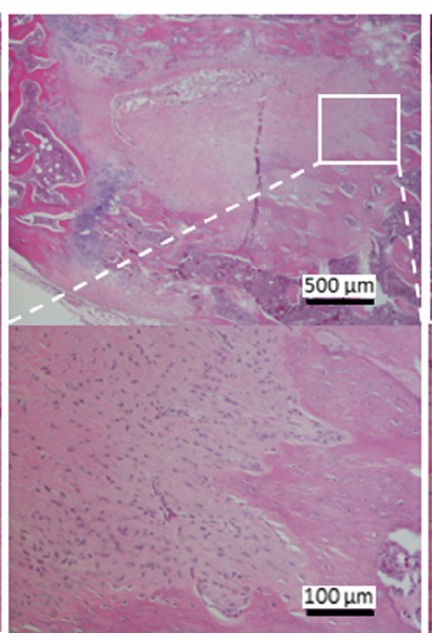

Male Test

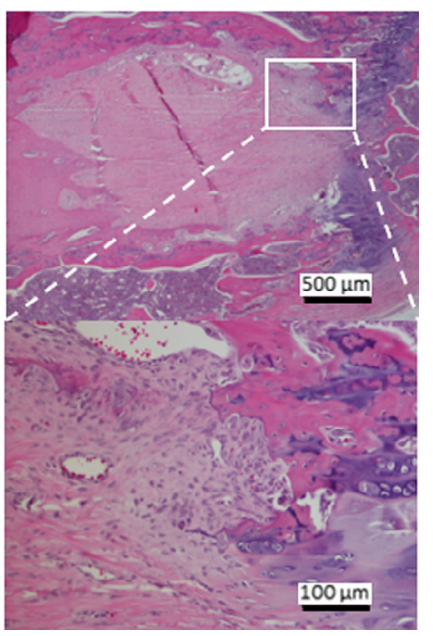

FIGURE 3. Representative photographs of histological images from the entire defect and higher magnification of the rectangular lines, after HE staining, from femur defect site of animal from control and test groups of both genders, at 3 weeks after surgery. 
(A)

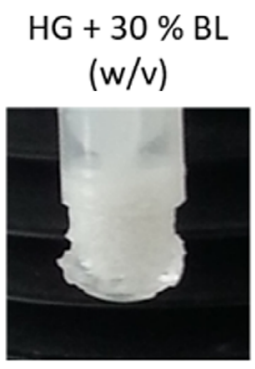

$\mathrm{HG}+40 \% \mathrm{BL}$ $(w / v)$

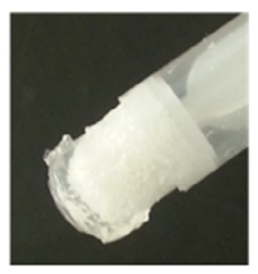

$H G+60 \% B L$ $(w / v)$

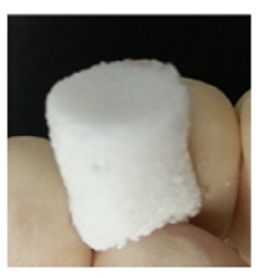

(B)

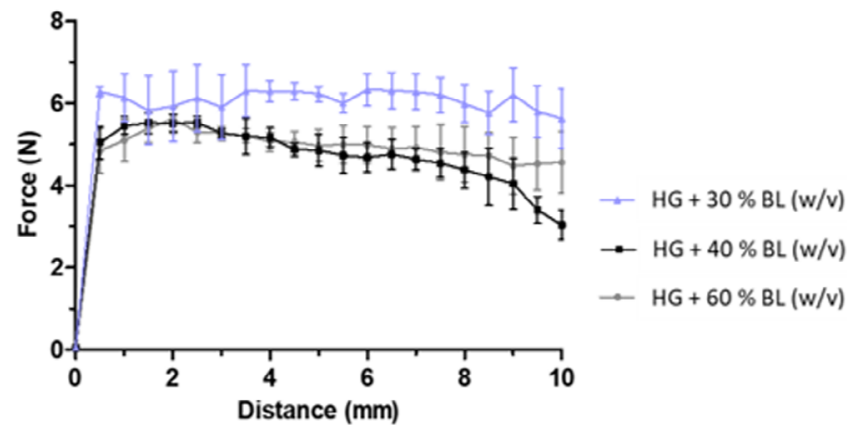

FIGURE 4. Preparation of the injectable bone substitute: macroscopic evaluation of dextrin-based hydrogel (HG) with different concentrations of Bonelike $(B L)$ granules, after completely gelation reaction $(A)$ and the results of the injectability test (B).

micro-CT images of treated animals [Fig. 5(B)] also allowed to observe the presence of BL granules uniformly distributed within the gap region after 3 and 6 weeks. During the sample collection after sacrificing the animals, no macroscopic evidence of adverse tissue reaction was observed, demonstrating again the biocompatibility of the formulation $\mathrm{HG}+\mathrm{BL}$.

\section{DISCUSSION}

Following implantation of biomaterials, lixiviates, or degradation products may be released and spread all over the body. Therefore, the systemic toxicity assessment is of great importance to demonstrate the safety of such biomaterials. The dextrin-based HG is composed by ODEX and ADH linked by hydrazine bonds, which are susceptible to hydrolysis under aqueous environment. ${ }^{20}$ In a previous study, the in vivo biocompatibility of the HG after subcutaneous implantation in a rat model was assessed. It was verified that after 15 days small amount of HG residues were still present in the implant sites. $^{22}$ In the present work, the systemic toxicity of the HG after implantation in a bone defect was evaluated over a period of 3 weeks. The results obtained in the present study clearly demonstrated that the ODEX-based HG did not promote any metabolic abnormalities and no toxic effects on vital organs, like liver or kidney, after its implantation in bone defects, demonstrating its safety.
Dextrin is a biocompatible, nonimmunogenic polysaccharide and biodegradable by alpha-amylases. Furthermore, the molecular weight of dextrin is appropriate to ensure renal elimination, thus excluding the threat of progressive accumulation after repeated administration. ${ }^{34,35}$ However, dextrin is still relatively unexplored in biomedical field, being clinically used as a peritoneal dialysis (PD) solution ${ }^{36-38}$ and as wound dressing agent. ${ }^{39}$ Dextrin displays important chemical features, such as solubility in both water and DMSO, and availability of hydroxyl groups, allowing an easy chemical modification of its backbone. ${ }^{40,41}$ It is known that dextrin backbone modification and/or the degree of such modifications can affect the biodegradability of the dextrin. ${ }^{35,42,43}$ During the last years, few researchers have successfully developed and characterized dextrin-based $\mathrm{HGs}^{20,44-49}$ and nanogels ${ }^{34,50-55}$ for drug delivery and tissue engineering applications. However, in vivo toxicity studies are scarce and focus mainly local degradation and inflammatory response in subcutaneous assays, ${ }^{22,42}$ or in vivo drug release studies for nanogels. ${ }^{52,56}$ Das et al. ${ }^{46}$ synthesized and characterized a biodegradable crosslinked HG, consisting of polylactic acid (PLA) and dextrin in the presence of crosslinker $\mathrm{N}, \mathrm{N}$ methylenebisacrylamide-Dxt- $g$-PLA HG. The acute toxicity of the Dxt- $g$-PLA HG was assessed in mice after a single orally administered dose of HG (2000 mg/kg body weight), and no
(A)

0 weeks

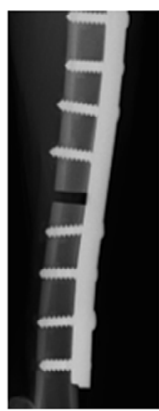

Control

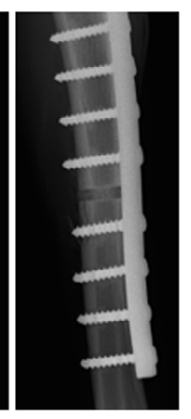

Test
(B)
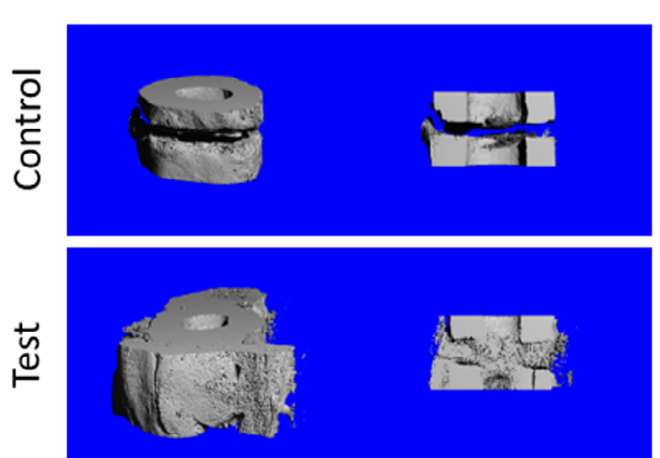

6 weeks
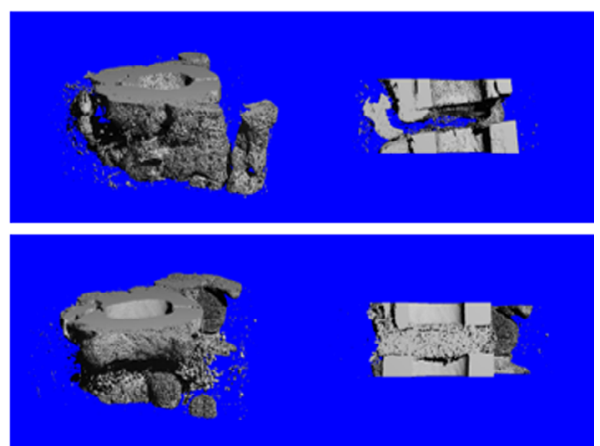

FIGURE 5. Representative radiographic and micro-CT images of tibial fracture from control and test groups: (A) radiographic images of tibia after surgery ( 0 week) from control and test groups and (B) micro-CT reconstruction images of tibia after 3 and 6 weeks, showing the whole sample and the hollow cylindrical region of interest within the whole sample. 
mortality was observed within 12 weeks. ${ }^{46}$ Relating to dextrin-based nanogels, Gonçalves et al. $^{50}$ have developed self-assembling nanogels of dextrin-Dextrin-VA-SC16 (vinyl acrylate [VA], SC16: alkyl chain)-and studied their organ biodistribution after intravenous administration in rodent models. ${ }^{57}$ The radioactivity of the Dextrin-VA-SC16 nanogels was mainly located in the organs of the Mononuclear Phagocytic System (liver and spleen) and kidneys. The reduction of the radioactivity levels observed after $2 \mathrm{~h}$ suggested that the material does not accumulate in the organs, presumably being metabolized and excreted. Indeed, some renal uptake of the nanogels, and excretion in the urine was detected. ${ }^{57}$

Increased levels of DNA damage and ineffective repair mechanisms are the underlying biomolecular events in the pathogenesis of most of the life-threatening diseases, like cancer and degenerative diseases. ${ }^{58}$ It is generally accepted that DNA damage in blood cells can reflect the level of oxidative stress in the body, albeit not always is clear whether this damage could be either the cause or the effect of diseases. ${ }^{59}$ Accordingly, genotoxicity assessment in parallel with systemic toxicity evaluation may add more information about the HG safety. The comet assay results demonstrated that that HG did not induce DNA damage. The results herein obtained with blood cells are in agreement with in vitro findings in human lymphoblastoid TK6 cells exposed to different concentrations of the HG that revealed no DNA and chromosomal damage, as assessed by the micronucleus and comet assays, ${ }^{23}$ supporting the view that the HG is genocompatible.

Although the use of isolated PBMC for DNA damage analysis by the comet assay has been well established, the advantage of using whole-blood for in vivo studies is here highlighted, mainly in situations where time is a limiting factor as more samples can be handled in a short period of time, since no cell separation procedures are necessary. ${ }^{59,60}$ This option is also advantageous when sample volume is critical, for instance, when younger rats or mice (e.g., C57BL/6) are used and/or when many different analyses should be performed with blood. In this study, it was demonstrated that only a few microliters of whole blood $(5 \mu \mathrm{L})$ could be used directly for comet assay analysis, much less than it is required for isolation of PBMC $(100 \mu \mathrm{L})$. It was also demonstrated that whole-blood approach provides reliable results for genotoxicity biomonitoring in rodent models, since the conclusions resulting from PBMC do not differ from those derived from whole-blood cells, as previously reported by Chuang and $\mathrm{Hu}^{60}$

By analysis of the implanted site - femur, it was possible to verify that HG does not affect the bone healing process, displaying a good histocompatibility. As the performed defect was a noncritical defect, it will heal spontaneously over the time. In a previous study, the HG was evaluated for inflammatory response, using subcutaneous implants in rats. ${ }^{22}$ In that study, histological analysis after 3 and 15 days showed typical acute and chronic inflammatory responses, respectively. HG was scored as slightly irritant after 3 days of implantation and as nonirritant after 15 days. Several studies on HGs containing aldehyde-modified polysaccharides have shown biocompatibility, safety, and good performance in vivo in diverse biomedical applications, such as HGs for prevention of postoperative adhesions, ${ }^{61-63}$ surgical haemostatics, ${ }^{64}$ bioadhesives, and sealants. ${ }^{65,66}$ In this study, the bone biocompatibility of the ODEX-based HG has been demonstrated, which supports its use as a safe candidate for the development of injectable bone substitute.

The skin sensitization test indicated that $\mathrm{HG}$ did not induce any allergic reactions and corroborate the results obtained in the systemic toxicity assay. Polymeric glucosebased pharmaceutical products have been reported to induce allergic reactions, including anaphylaxis. This is the case of dextran ${ }^{67,68}$ and hydroxyethyl starch, ${ }^{69,70}$ both used as plasma volume expanders. Concerning to dextrin, it is being clinically used as a PD solution (icodextrin). ${ }^{36,37}$ It is generally safe and well tolerated by PD patients, but there are few reports of acute self-limiting allergic hypersensitivity reaction to icodextrin, such as skin rashes. ${ }^{71,72}$ Our $\mathrm{HG}$ is composed mainly by dextrin $(\approx 95 \%)$, containing about $40 \%$ of residues with dialdehydes. ${ }^{25}$ The obtained results suggest that such modification did not promote any skin sensitization.

Dextrin-based HG was conceived as a multifunctional and injectable matrix able to carry and stabilize other materials and/or cells in medical procedures. ${ }^{20-22}$ Specifically, in bone regeneration procedures where synthetic bone grafts are used, an injectable carrier and/or granules stabilizer matrix may ease the clinical application/handling of grafts or drugs, promoting a suitable environment for regeneration. ${ }^{9}$ In this work, HG was combined with glass-reinforced HAP particles $(250-500 \mu \mathrm{m})$, registered as Bonelike. ${ }^{73} \mathrm{BL}$ is a three-phase material, consisting of $\alpha$ - and $\beta$-TCP phases homogeneously dispersed in the HAP matrix, resulting in improved mechanical properties and enhanced bioactivity, compared to the commercial HAP. ${ }^{73,74}$ Furthermore, the presence of glass in this formulation allows the introduction of several ions into BL composition, such as magnesium, fluoride, and sodium, making it possible to achieve a chemical composition closer to the mineral phase of the bone. ${ }^{75}$ Clinical trials revealed its remarkable potential of osteoconductivity and osseointegration on orthopedic and dental applications. ${ }^{76-79}$ However, clinical applications were often performed using autologous blood as a carrier for the granules, which raises the need for a more adequate and less invasive vehicle to better stabilize the granules in large defects or unstable sites, avoiding dispersion or medullar infiltration. Moreover, the development of a moldable/injectable formulation will increase the diversity of clinical cases in which BL can be applied. In this study, the HG was successfully combined with BL granules to obtain a moldable/injectable bone substitute. The formulation containing $60 \%$ of BL was chosen to be tested in in vivo studies, since it was found (1) to be injectable, (2) to envelop and aggregate the BL granules well and uniformly distributed, and (3) able to maintain a whole and moldable structure during and after the injection.

In order to evaluate the effectiveness of the obtained moldable/injectable bone substitute, a tibial fracture in a goat model was used. The tibial fracture results demonstrated the capability of the HG to maintain the granules' cohesion and stabilize them within the defect. Additionally, 
the HG was able to ensure effective handling properties of the $\mathrm{HG}+\mathrm{BL}$ formulation. It is important to note that BL granules were not designed to withstand load-bearing bone defects and the tibial fracture was used in this work as an extreme model to demonstrate the ability of the HG on the BL granules' stability and cohesion within the gap region.

Covalently and ionically crosslinked HGs are generally composed by two components (polymer and cross-linking agent, or polymers modified with chemically complementary groups) which can easily be mixed by the surgeon under aseptic conditions and injected/implanted. ${ }^{9}$ One advantage of these systems in relation to others (e.g., sensitive to temperature, UV crosslinked) is the ability of the surgeons to follow gelation process: after mixing the formulation, the cross-linking process starts, the mixed solution becomes more viscous over time as it gels. During this process, the surgeon can choose the best moment in which the formulation can be implanted into the defect, since depending on defects type and size very moldable/viscous solutions or liquid ones may be preferable. Many studies have reported gelling times from seconds to several minutes for this kind of injectable bone substitutes. ${ }^{9,14}$ Surgeons generally advise $5-30 \mathrm{~min}$ as a suitable gelation time. $^{80}$ This was found to be fairly short for the HG alone, when the cross-linking reaction occurs in situ between the rheometer plates, presenting a gel point $\left(G^{\prime}=G^{\prime \prime}\right)$ after $1 \mathrm{~min}$ and reaching stability after around $4 \mathrm{~min}$ (data not shown). However, when combined with BL granules, the gelation time of the bone substitute increased. The surgeons have found that after 10-15 min the formulation (ODEX + ADH + BL) was easy to handle/implant into the defect, without loss the granules' cohesiveness. It is important to note that a rheological analysis of the HG with BL granules incorporated is not possible, given the sample's heterogeneity. Another advantage consists in the ability to add bioactive agents, such as proteins, cells, at the time the formulation are being prepared, to improve the bone healing process. ${ }^{7,9,13,16,17}$ The results showed that the HG is an effective matrix to carrier, featuring good handling and stabilization of the granular-based SBSs.

\section{CONCLUSION}

In the present study, it was demonstrated that the ODEX-based HG did not induce any systemic toxic effect, neither impaired the bone repair/regeneration process. The HG was successfully combined with BL granules to obtain a moldable/injectable bone substitute. The tibial fracture results showed that the HG allowed the stabilization of the BL granules into the defect, ensuring effective handling properties of the HG + BL formulation, as well as, an efficient cohesion of the granules. Thus, this work addressed technical requirements of IBS currently unmet and requiring further research and development. Other studies have been performed to better characterize the bone healing process of $\mathrm{HG}+\mathrm{BL}$ formulations in critical-sized defects.

\section{ACKNOWLEDGMENTS}

Isabel Pereira was supported by the grant SFRH/BD/ 90066/ 2012 from FCT, Portugal. This work was funded by the project "DEXGELERATION - Advanced solutions for bone regeneration based on dextrin hydrogels" (Norte-07-0202-FEDER-038853) and the project "iBone Therapies - innovative therapies for bone regeneration" (NORTE-01-0247-FEDER-003262).

The authors acknowledge the funding from FCT under the scope of the strategic funding of UID/BIO/04469/2013 and UID/BIM/04293/2013 units and COMPETE 2020 (POCI-010145-FEDER-006684), BioTecNorte operation (NORTE-010145-FEDER-000004) and NORTE-01-0145-FEDER-000012 funded by FEDER under the scope of Norte2020-Programa Operacional Regional do Norte.

\section{CONFLICT OF INTEREST}

No benefit of any kind will be received either directly or indirectly by the authors.

\section{REFERENCES}

1. Stevens MM. Biomaterials for bone tissue engineering. Mater Today 2008;11:18-25.

2. Amini AA, Nair LS. Injectable hydrogels for bone and cartilage repair. Biomed Mater 2012;7:024105.

3. Bohner M. Resorbable biomaterials as bone graft substitutes. Mater Today 2010;13:24-30.

4. Campana V, Milano G, Pagano E, Barba M, Cicione C, Salonna G, Lattanzi W, Logroscino $G$. Bone substitutes in orthopaedic surgery: From basic science to clinical practice. J Mater Sci Mater Med 2014; 25:2445-2461.

5. Bongio M, van den Beucken JJJP, Leeuwenburgh SCG, Jansen JA. Development of bone substitute materials: From 'biocompatible' to 'instructive'. J Mater Chem 2010;20:8747.

6. Navarro M, Michiardi A, Castaño O, Planell JA. Biomaterials in orthopaedics. J R Soc Interface 2008;5:1137-1158.

7. D'Este M, Eglin D. Hydrogels in calcium phosphate moldable and injectable bone substitutes: Sticky excipients or advanced 3-D carriers? Acta Biomater 2013;9:5421-5430.

8. Utech S, Boccaccini AR. A review of hydrogel-based composites for biomedical applications: Enhancement of hydrogel properties by addition of rigid inorganic fillers. J Mater Sci 2016;51:271-310.

9. Pereira I, Rodrigues C, Rodrigues A, Oliveira M, Gama M. In: Rodriges L, Mota M, editors. Bioinspired Materials for Medical Applications. Duxford: Elsevier; 2017. p 241-271. https://doi.org/10. 1016/B978-0-08-100741-9.00009-7.

10. Fellah BH, Weiss P, Gauthier O, Rouillon T, Pilet P, Daculsi G, Layrolle $\mathrm{P}$. Bone repair using a new injectable self-crosslinkable bone substitute. J Orthop Res Off Publ Orthop Res Soc 2006;24:628-635.

11. Trojani C, Boukhechba F, Scimeca JC, Vandenbos F, Michiels JF, Daculsi G, Boileau P, Weiss P, Carle GF, Rochet N. Ectopic bone formation using an injectable biphasic calcium phosphate/Si-HPMC hydrogel composite loaded with undifferentiated bone marrow stromal cells. Biomaterials 2006;27:3256-3264.

12. Gaharwar AK, Dammu SA, Canter JM, Wu C-J, Schmidt G. Highly extensible, tough, and elastomeric nanocomposite hydrogels from poly(ethylene glycol) and hydroxyapatite nanoparticles. Biomacromolecules 2011;12:1641-1650.

13. Gao C, Cai Y, Kong X, Han G, Yao J. Development and characterization of injectable chitosan-based hydrogels containing dexamethasone/ rhBMP-2 loaded hydroxyapatite nanoparticles. Mater Lett 2013;93: 312-315.

14. Han Y, Zeng Q, Li H, Chang J. The calcium silicate/alginate composite: Preparation and evaluation of its behavior as bioactive injectable hydrogels. Acta Biomater 2013;9:9107-9117.

15. Killion JA, Kehoe S, Geever LM, Devine DM, Sheehan E, Boyd D, Higginbotham CL. Hydrogel/bioactive glass composites for bone regeneration applications: Synthesis and characterisation. Mater Sci Eng C: Mater Biol Appl 2013;33:4203-4212.

16. Killion JA, Geever LM, Devine DM, Farrell H, Higginbotham CL. Compressive strength and bioactivity properties of photopolymerizable hybrid composite hydrogels for bone tissue engineering. Int J Polym Mater Polym Biomater 2014;63:641-650. 
17. Killion JA, Geever LM, Devine DM, Higginbotham CL. Fabrication and in vitro biological evaluation of photopolymerisable hydroxyapatite hydrogel composites for bone regeneration. J Biomater Appl 2014;28: 1274-1283.

18. Nguyen TP, Doan BHP, Dang DV, Nguyen CK, Tran NQ. Enzymemediated in situ preparation of biocompatible hydrogel composites from chitosan derivative and biphasic calcium phosphate nanoparticles for bone regeneration. Adv Nat Sci Nanosci Nanotechnol 2014;5:015012.

19. Bongio $M$, van den Beucken JJJ, Nejadnik MR, Tahmasebi Birgani Z, Habibovic P, Kinard LA, Kasper FK, Mikos AG, Leeuwenburgh SCG, Jansen JA. Subcutaneous tissue response and osteogenic performance of calcium phosphate nanoparticleenriched hydrogels in the tibial medullary cavity of guinea pigs. Acta Biomater 2013;9:5464-5474.

20. Molinos M, Carvalho V, Silva DM, Gama FM. Development of a hybrid dextrin hydrogel encapsulating dextrin nanogel as protein delivery system. Biomacromolecules 2012;13:517-527.

21. Silva DM, Nunes C, Pereira I, Moreira ASP, Domingues MRM, Coimbra MA, Gama FM. Structural analysis of dextrins and characterization of dextrin-based biomedical hydrogels. Carbohydr Polym 2014;114:458-466.

22. Silva DM, Caseiro AR, Amorim I, Pereira I, Faria F, Pereira T, Santos JD, Gama FM, Maurício AC. Inflammatory response to dextrin-based hydrogel associated with human mesenchymal stem cells, urinary bladder matrix and Bonelike ${ }^{\circledR}$ granules in rat subcutaneous implants. Biomed Mater 2016;11:065004.

23. Pereira I, Fraga S, Silva S, Teixeira JP, Gama M. In vitro genotoxicity assessment of an oxidized dextrin-based hydrogel for biomedical applications. J Appl Toxicol 2018;39:639-649. https://doi. org/10.1002/jat.3754.

24. ISO 10993-1. Biological evaluation of medical devices-Part 1: Evaluation and testing within a risk management process; 2009. https:// www.iso.org/standard/44908.html

25. Pereira I, Simões J, Evtyugin DV, Rouif S, Coimbra MA, Domingues MRM, Gama M. Effects of gamma irradiation and periodate oxidation on the structure of dextrin assessed by mass spectrometry. Eur Polym J 2018;103:158-169.

26. Cortez PP, Atayde LM, Silva MA, Armada-da-Silva P, Fernandes MH, Afonso A, Lopes MA, Maurício AC, Santos JD. Characterization and preliminary in vivo evaluation of a novel modified hydroxyapatite produced by extrusion and spheronization techniques. J Biomed Mater Res Part B: Appl Biomater 2011;99B:170-179.

27. Santos, JD, Lopes, MA, Silva, MA. Hydroxyapatite and bioglassbased pellets, production process and applications of thereof; 2010. https://patents.google.com/patent/WO2010021559A1/en

28. OECD. Guidance Document on the Recognition, Assessment and Use of Clinical Signs as Human Endpoints for Experimental Animals Used in Safety Evaluation. Paris: OECD Publishing; 2002. doi: https://doi.org/10.1787/9789264078376-en

29. ISO 10993-11. Biological evaluation of medical devices-Part 11: Tests for systemic toxicity; 2006. https://www.iso.org/standard/35977.html

30. ISO 10993-10. Biological evaluation of medical devices-Part 10: Tests for irritation and skin sensitization; 2010. https://www.iso.org/ standard/40884.html

31. OECD. Test No. 406: Skin Sensitisation, OECD Guidelines for the Testing of Chemicals, Section 4, Paris: OECD Publishing; 1992. https://doi.org/10.1787/9789264070660-en

32. Giknis MLA, Clifford CB. Clinical laboratory parameters for Crl:WI (Han). Charles River Laboratories; 2008. https://www.criver.com/ sites/default/files/resources/rm_rm_r_Wistar_Han_clin_lab_parameters_ 08.pdf.

33. Tice RR, Agurell E, Anderson D, Burlinson B, Hartmann A, Kobayashi H, Miyamae Y, Rojas E, Ryu JC, Sasaki YF. Single cell gel/comet assay: Guidelines for in vitro and in vivo genetic toxicology testing. Environ Mol Mutagen 2000;35:206-221.

34. Carvalho V, Castanheira P, Faria TQ, Gonçalves C, Madureira $P$, Faro C, Domingues L, Brito RMM, Vilanova M, Gama M. Biological activity of heterologous murine interleukin-10 and preliminary studies on the use of a dextrin nanogel as a delivery system. Int $\mathrm{J}$ Pharm 2010;400:234-242.

35. Hreczuk-Hirst D, Chicco D, German L, Duncan R. Dextrins as potential carriers for drug targeting: Tailored rates of dextrin degradation by introduction of pendant groups. Int J Pharm 2001;230:57-66.
36. Peers E, Gokal R. Icodextrin provides long dwell peritoneal dialysis and maintenance of intraperitoneal volume. Artif Organs 1998; 22:8-12.

37. Takatori $Y$, Akagi S, Sugiyama $H$, Inoue J, Kojo S, Morinaga $H$, Nakao K, Wada J, Makino $\mathrm{H}$. Icodextrin technique survival rate in peritoneal dialysis patients with diabetic nephropathy by improving body fluid management: A randomized controlled trial. Clin J Am Soc Nephrol 2011;6:1337-1344.

38. Treetharnmathurot B, Dieudonné L, Ferguson EL, Schmaljohann D, Duncan R, Wiwattanapatapee R. Dextrin-trypsin and ST-HPMAtrypsin conjugates: Enzyme activity, autolysis and thermal stability. Int J Pharm 2009;373:68-76.

39. DeBusk, AOV, Alleman, T. Method for preparing medical dressings; 2005. https://patents.google.com/patent/WO2004002460A1/en

40. Das D, Pal S. Modified biopolymer-dextrin based crosslinked hydrogels: Application in controlled drug delivery. RSC Adv 2015;5: 25014-25050.

41. Gonçalves C, Moreira SM, Carvalho V, Silva DM, Gama M. In: Mishra M, editor. Encyclopedia of Biomedical Polymers and Polymeric Biomaterials. New York: Taylor \& Francis; 2016. p 2634-2649.

42. Moreira S, Gil da Costa RM, Guardão L, Gärtner F, Vilanova M, Gama M. In vivo biocompatibility and biodegradability of dextrinbased hydrogels. J Bioact Compat Polym 2010;25:141-153.

43. Gonçalves C, Torrado E, Martins T, Pereira P, Pedrosa J, Gama M. Dextrin nanoparticles: Studies on the interaction with murine macrophages and blood clearance. Colloids Surf B: Biointerfaces 2010; 75:483-489.

44. Carvalho J, Gonçalves C, Gil AM, Gama FM. Production and characterization of a new dextrin based hydrogel. Eur Polym J 2007;43: 3050-3059.

45. Carvalho J, Moreira S, Maia J, Gama FM. Characterization of dextrin-based hydrogels: Rheology, biocompatibility, and degradation. J Biomed Mater Res Part A 2009;9999A:398-399.

46. Das D, Das R, Mandal J, Ghosh A, Pal S. Dextrin crosslinked with poly(lactic acid): A novel hydrogel for controlled drug release application. J Appl Polym Sci 2014;131:40039.

47. Das D, Pal S. Dextrin/poly (HEMA): $\mathrm{pH}$ responsive porous hydrogel for controlled release of ciprofloxacin. Int J Biol Macromol 2015;72: 171-178.

48. Das D, Mukherjee S, Pal A, Das R, Sahu SG, Pal S. Synthesis and characterization of biodegradable copolymer derived from dextrin and poly(vinyl acetate) via atom transfer radical polymerization. RSC Adv 2016;6:9352-9359.

49. Roy A, Maity PP, Dhara S, Pal S. Biocompatible, stimuli-responsive hydrogel of chemically crosslinked $\beta$-cyclodextrin as amoxicillin carrier. J Appl Polym Sci 2018;135:45939.

50. Gonçalves C, José A, Martins FMG. Self-assembled nanoparticles of dextrin substituted with hexadecanethiol. Biomacromolecules 2007;8:392-398.

51. Manchun S, Dass CR, Sriamornsak P. Designing nanoemulsion templates for fabrication of dextrin nanoparticles via emulsion cross-linking technique. Carbohydr Polym 2014;101:650-655.

52. Manchun S, Dass CR, Cheewatanakornkool K, Sriamornsak P. Enhanced anti-tumor effect of $\mathrm{pH}$-responsive dextrin nanogels delivering doxorubicin on colorectal cancer. Carbohydr Polym 2015;126:222-230.

53. Das D, Patra P, Ghosh $P$, Rameshbabu AP, Dhara S, Pal S. Dextrin and poly(lactide)-based biocompatible and biodegradable nanogel for cancer targeted delivery of doxorubicin hydrochloride. Polym Chem 2016;7:2965-2975.

54. Das D, Rameshbabu AP, Ghosh P, Patra P, Dhara S, Pal S. Biocompatible nanogel derived from functionalized dextrin for targeted delivery of doxorubicin hydrochloride to MG 63 cancer cells. Carbohydr Polym 2017;171:27-38.

55. Das D, Rameshbabu AP, Patra P, Ghosh P, Dhara S, Pal S. Biocompatible amphiphilic microgel derived from dextrin and poly(methyl methacrylate) for dual drugs carrier. Polymer (Guildf) 2016;107:282-291.

56. Carvalho V, Castanheira P, Madureira P, Ferreira SA, Costa C, Teixeira JP, Faro C, Vilanova M, Gama M. Self-assembled dextrin nanogel as protein carrier: Controlled release and biological activity of IL-10. Biotechnol Bioeng 2011;108:1977-1986.

57. Gonçalves C, Ferreira MFM, Santos AC, Prata MIM, Geraldes CFGC, Martins JA, Gama FM. Studies on the biodistribution of dextrin nanoparticles. Nanotechnology 2010;21:295103. 
58. Gunasekarana V. A comprehensive review on clinical applications of comet assay. J Clin Diag Res 2015;9:GE01-GE05.

59. Giovannelli L, Pitozzi V, Riolo S, Dolara P. Measurement of DNA breaks and oxidative damage in polymorphonuclear and mononuclear white blood cells: A novel approach using the comet assay. Mutat Res Toxicol Environ Mutagen 2003;538:71-80.

60. Chuang $\mathrm{C}-\mathrm{H}, \mathrm{Hu} \mathrm{M}-\mathrm{L}$. Use of whole blood directly for single-cell gel electrophoresis (comet) assay in vivo and white blood cells for in vitro assay. Mutat Res Toxicol Environ Mutagen 2004;564:75-82.

61. Athanasiadis $T$, Beule AG, Robinson BH, Robinson SR, Shi Z, Wormald PJ. Effects of a novel chitosan gel on mucosal wound healing following endoscopic sinus surgery in a sheep model of chronic rhinosinusitis. Laryngoscope 2008;118:1088-1094.

62. Ito T, Yeo Y, Highley CB, Bellas E, Benitez CA, Kohane DS. The prevention of peritoneal adhesions by in situ cross-linking hydrogels of hyaluronic acid and cellulose derivatives. Biomaterials 2007;28: 975-983.

63. Lauder CIW, Strickland A, Maddern GJ. Use of a modified chitosan-dextran gel to prevent peritoneal adhesions in a porcine hemicolectomy model. J Surg Res 2012;176:448-454.

64. Rajiv S, Harding M, Bassiouni A, Jardeleza C, Drilling A, James C, $\mathrm{Ha}$ T, Moratti S, Robinson S, Wormald PJ. The efficacy and safety of chitosan dextran gel in a burr hole neurosurgical sheep model. Acta Neurochir 2013;155:1361-1366.

65. Artzi N, Shazly T, Baker AB, Bon A, Edelman ER. Aldehyde-amine chemistry enables modulated biosealants with tissue-specific adhesion. Adv Mater 2009;21:3399-3403.

66. Hoffmann B, Volkmer E, Kokott A, Augat $P$, Ohnmacht $M$, Sedlmayr N, Schieker M, Claes L, Mutschler W, Ziegler G. Characterisation of a new bioadhesive system based on polysaccharides with the potential to be used as bone glue. J Mater Sci Mater Med 2009;20:2001-2009.

67. Zinderman CE, Landow L, Wise RP. Anaphylactoid reactions to dextran 40 and 70: Reports to the United States Food and Drug Administration, 1969 to 2004. J Vasc Surg 2006;43:1004-1009.

68. Zanoni G, Puccetti A, Dolcino M, Simone R, Peretti A, Ferro A, Tridente $G$. Dextran-specific IgG response in hypersensitivity reactions to measles-mumps-rubella vaccine. J Allergy Clin Immunol 2008;122:1233-1235.
69. Ebo DG, Schuerwegh A, Stevens WJ. Anaphylaxis to starch. Allergy 2000;55:1098-1099.

70. Kim HJ, Kim SY, Oh MJ, Kim JM. Anaphylaxis induced by hydroxyethyl starch during general anesthesia: A case report. Korean $\mathrm{J}$ Anesthesiol 2012;63:260-262.

71. Goldsmith D, Jayawardene S, Sabharwal N, Cooney K. Allergic reactions to the polymeric glucose-based peritoneal dialysis fluid icodextrin in patients with renal failure. Lancet 2000;355:897.

72. Ankur G, Mohan B. Icodextrin and skin rash: Unusual presentation. Indian J Nephrol 2012;22:62-63.

73. Atayde LM, Cortez PP, Afonso A, Santos M, Maurício AC, Santos JD. Morphology effect of bioglass-reinforced hydroxyapatite $\left(\right.$ Bonelike ${ }^{\circledR}$ ) on osteoregeneration. J Biomed Mater Res Part B: Appl Biomater 2015;103:292-304.

74. Lopes M, Knowles J, Santos J, Monteiro F, Olsen I. Direct and indirect effects of $\mathrm{P} 2 \mathrm{O} 5$ glass reinforced-hydroxyapatite composites on the growth and function of osteoblast-like cells. Biomaterials 2000; 21:1165-1172.

75. Cortez PP, Silva MA, Santos M, Armada-da-Silva P, Afonso A, Lopes MA, Santos JD, Maurício AC. A glass-reinforced hydroxyapatite and surgical-grade calcium sulfate for bone regeneration: in vivo biological behavior in a sheep model. J Biomater Appl 2012;27:201-217.

76. Gutierres M, Hussain NS, Afonso A, Almeida L, Cabral T, Lopes MA, Santos JD. Biological behaviour of Bonelike ${ }^{\circledR}$ graft implanted in the tibia of humans. Key Eng Mater 2005;284-286:1041-1044.

77. Gutierres M, Hussain NS, Lopes MA, Afonso A, Cabral AT, Almeida L, Santos JD. Histological and scanning electron microscopy analyses of bone/implant interface using the novel Bonelike ${ }^{\circledR}$ synthetic bone graft. J Orthop Res 2006;24:953-958.

78. Sousa RC, Lobato JV, Maurício AC, Hussain NS, Botelho CM, Lopes MA, Santos JD. A clinical report of bone regeneration in maxillofacial surgery using Bonelike ${ }^{\circledR}$ synthetic bone graft. J Biomater Appl 2008;22:373-385.

79. Lobato JV, Sooraj Hussain N, Botelho CM, Maurício AC, Lobato JM, Lopes MA, Afonso A, Ali N, Santos JD. Titanium dental implants coated with Bonelike ${ }^{\circledR}$ : Clinical case report. Thin Solid Films 2006; 515:279-284.

80. Tan R, Niu X, Gan S, Feng Q. Preparation and characterization of an injectable composite. J Mater Sci Mater Med 2009;20:1245-1253. 